\title{
Inclusion is for Everybody: International Day of Disabled Persons
}

International Day of Disabled persons is celebrated for the equality of the disabled people and for their upliftment. In 1981, the United Nations proclaimed December $3^{\text {rd }}$ as a recognised day for the celebration of the achievements of people living with disabilities across the world. It is also a day upon which we promote awareness of the challenges faced by over 1 billion people living with disabilities, and the role communities and societies play in accelerating the eradication of barriers to social inclusion, equity, participation and citizenship.

People with disabilities do not enjoy access to society on an equal basis with others, which includes areas of transportation, employment, and education as well as social and political participation. The right to participate in public life is essential to create stable democracies, active citizenship and reduce inequalities in society. Disability may increase the risk of poverty, through lack of employment and education opportunities, lower wages, and increased cost of living with a disability.

People with disabilities experience significant disadvantages when it comes to health such as they are more likely to have heart disease, stroke, diabetes, or cancer than adults without disabilities. It is observed that the health care of people with disabilities is still restricted to rehabilitation centres and other related services, which can compromise their access to services. The issue of access to health services may be even more problematic for people with motor disabilities, whose limitations require there to be adequate means of transportation in order to travel which subsequently results in a missed opportunity to receive health care which in itself can make the person's situation worse.

Now the question arises, what we can do to provide support to the people with disability? Support can be provided by organising education and counselling programs that promote physical activity, improve nutrition or reduces the use of tobacco, alcohol or drugs. Counters and service windows can be made low enough for everyone to reach. Sidewalk ramps can be made everywhere like in hospitals, schools and shopping area to make it convenient for the peoples on wheelchairs. Floor spaces and hallways should be free from equipment and other barriers.

All across the globe, persons with disabilities experience higher rates of unemployment and underemployment than non-disabled persons. When employed, they are also more likely to have low paid jobs with poor career prospects than people without disabilities. We should built an inclusive workforce where people with disabilities can actively participate like establishing an enterprise-wide team consisting of executives, managers and employees with disabilities to support and advance the recruiting, hiring, retention and promotion of individuals with disabilities, Including disability as part of all of the company's diversity policies and activities. This includes using the words "disability" and "people with disabilities" in statements defining the company's diversity policies, inviting disability organizations and people with disabilities to the company's diversity events, and recognizing that people with disabilities are part of the company's other diverse communities, encouraging workers with disabilities and other employees to identify barriers and individual and systemic concerns without fear of reprisal, and also providing mechanisms to allow them to provide this information anonymously or confidentially.

It is critical to ensure that full and equal participation of person with disabilities in all spheres of society and create enabling environment by, for and with persons with disabilities. In order to achieve goals of inclusiveness and equality, it is important for academic institutions, persons with disabilities and the organisations that represent them, to collectively work as a team.

\section{REFERENCES}

1.http://www.un.org/en/events/disabilitiesday/index.s html [Last Accessed on $5^{\text {th }}$ October 2018] 2.https://www.worldbank.org/en/topic/disability [Last Accessed on $15^{\text {th }}$ October 2018] 
Cite this article as:

Gupta A. Inclusion is for Everybody: International Day of Disabled Persons.

Int Healthc Res J. 2018;2(9):205-206. doi: 10.26440/ihrj.v2ig.181

Author Details \& Corresponding Address:

Dr. Ankur Gupta

MDS (Orthodontics and Dentofacial Orthodontics)

Consultant Orthodontist and Private Practitioner

Gupta Dental Care and orthodontic Centre

RZ 40, Naya Bazar Najafgarh, New Delhi 110043
For article enquiry/author contact details, e-mail at: manuscriptenquiry.ihrj@gmail.com 